
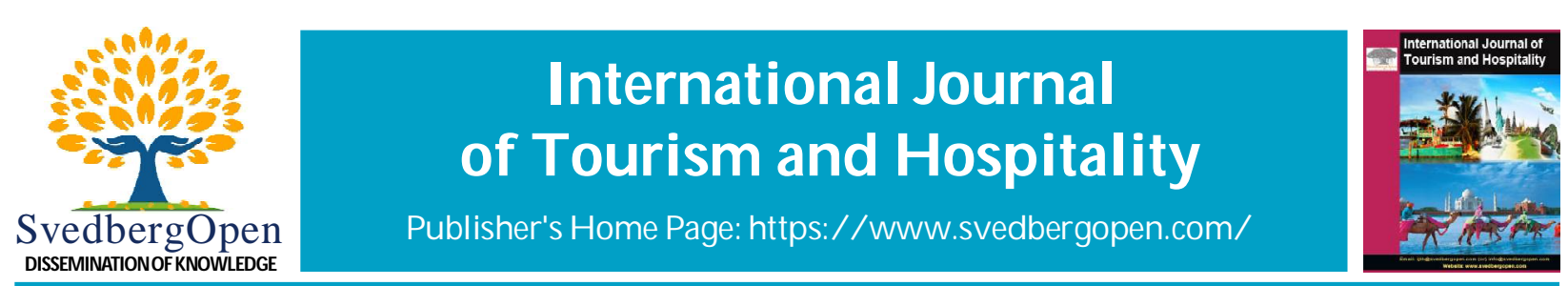

Research Paper

O pen A ccess

\title{
SWOT analysis of the community extension services conducted by hospitality and tourism management programs: Strategies for service enhancement
}

Canet, Lena ${ }^{1 *}$

${ }^{1}$ De Luna, Maria Cecilia, Pulumbarit, Catherine, Reyes, Brigida, Sanchez, Cielito. E-mail: lena.canet@bulsu.edu.ph

\begin{tabular}{|c|c|}
\hline Article Info & $\begin{array}{l}\text { Abstract } \\
\text { The Community Extension Services conducted by Bulacan State University Hagonoy } \\
\text { Campus is guided by the University Extension Manual, which is designed to deliver pertinent } \\
\text { information directly to concerned parties and has been designed rigorously by the committee }\end{array}$ \\
\hline $\begin{array}{l}\text { Volume } 1 \text {, Issue 3, July } 2021 \\
\text { Received : } 17 \text { January } 2021 \\
\text { Accepted : } 12 \text { June } 2021 \\
\text { Published : } 05 \text { July } 2021 \\
\text { doi: 10.51483/IJTH.1.3.2021.36-40 }\end{array}$ & $\begin{array}{l}\text { To further strengthen the community extension services Bulacan State University - Hagonoy } \\
\text { Campus, the researchers sought to analyze and examine the Strengths, Weaknesses, } \\
\text { Opportunities, and Threats in implementing, monitoring, and evaluating its extension services } \\
\text { as a basis for service enhancement. In gathering the data to answer and clarify the research } \\
\text { problems, purposive selection was the sampling technique which will be employed in the } \\
\text { investigation. For the Extension Services that have been provided by BulSU-Hagonoy, } 50 \\
\text { out of the } 78 \text { respondents have participated in seminars for Climate Change Adaptation, } 7 \\
\text { out of } 78 \text { respondents for trainings and seminars in Historical and Cultural Heritage } \\
\text { Conservation, } 53 \text { out of } 78 \text { for Education which includes literacy trainings and seminars and } \\
\text { values formation seminars, and } 78 \text { or all of the respondents have participated in the Innovation } \\
\text { and Creativity which includes the livelihood and skills training and seminars extension } \\
\text { services. The data gathered revealed that out of the extension services conducted by the } \\
\text { Hospitality and Tourism Program, the livelihood and skills training and seminars are the } \\
\text { most participated extension services. } \\
\text { Keywords: Extension service, SWOT Analysis, Research and Extension, Skills training } \\
\text { (O 2021 Canet, Lena. This is an open access article under the CC BY license } \\
\text { (https://creativecommons.org/licenses/by/4.0/), which permits unrestricted use, } \\
\text { distribution, and reproduction in any medium, provided you give appropriate credit to the original } \\
\text { author(s)and the source, provide a link to the Creative Commons license, and indicate if changes were made. }\end{array}$ \\
\hline
\end{tabular}

\section{Introduction}

For almost nine years now, Bulacan State University (BulSU) Hagonoy Campus has been conducting community extension services in partnership with the different Local Government Units (LGUs) and Nongovernment Organizations (NGOs) within the locality of Hagonoy, Bulacan.

The community extension services offered by the campus are anchored in the Research-Based Extension Agenda of the University. They are aligned with local, regional, and national development thrusts such as CHED (Commission on Higher Education) priority 2011-2016, DOST (Department of Science and Technology) Harmonized National Research and Development Agenda 2017-2020, Philippine Development Plan 2017-2020, Central Luzon Development Plan 2017 2020, Provincial 7-Point Agenda and DSWD (Department of Social Welfare and Development) Thrust and Priorities. It is held once every semester or twice a year, aside from its annual sustainable extension program, the "Sambalaran (Sama Na Sa Pambayang Kaunlaran) Camp Project" that started in 2017 and was initiated by the Director of the University Extension Services, Dr. Victor C. Ramos.

\footnotetext{
* Corresponding author: Canet, Lena, De Luna, Maria Cecilia, Pulumbarit, Catherine, Reyes, Brigida, Sanchez, Cielito.
}

E-mail: lena.canet@bulsu.edu.ph 
Numerous projects and activities have been carried out and participated in by the faculty, students, and beneficiaries. BulSU-Hagonoy Campus currently has four departments, namely: Education Department (BSED, BEED, and BTLED Programs), Information Technology Department (BSIT Program), Hospitality and Tourism Management Department (BSHM and BSTM Programs), and BIT Department (Food Technology and Computer Technology Programs) and all departments are implementing the Research-Based Extension Agenda of the University such as, climate change adaptation, historical and cultural heritage conservation, education and innovation and creativity.

The community extension services conducted by the campus is guided by the University Extension Manual, which is designed to deliver pertinent information directly to concerned parties and has been designed rigorously by the committee tasked with its design and meets the quality standards expected by BulSU.

\section{Background of the study}

In a study conducted by Kau et al. (2019), it has been found out, based on the SWOT analysis for multiple extension services in the High Value Crop (HVC) program: insight for pluralistic extension policy, that the participation of numerous extensions in the HVC carries opportunities for the smallholder farmers. There is a need for effective coordination for services rendered by different agencies. Also, insufficient funding threatens the sustainability of continued engagement. Various extension agencies need to develop a common exit strategy and establish an influential stakeholders' forum for project sustainability.

To conduct an in-depth evaluation of the extension services and to offer insights into relevant best practices and key lessons from an assessment of public and private models of coffee extension, a US aid-funded program composed of multiple land grant universities and institutions agreed with the National Federation of Coffee Growers in 2012-2013. Mueller et al. (2012) cited that the coffee sector plays an essential role in Colombian agriculture. It represents about $17 \%$ of the agricultural output, and for about 2.2 million rural households, coffee is the primary source of income. The National Federation of Coffee Growers has provided extension services to its constituents since 1927. Still, recent developments in the domestic global coffee market are now posing new challenges requiring careful reassessment of the extension services. One is the advancement in information technologies that offer new opportunities in the provision of extension services.

Although there was no study regarding the community extensions accomplished by the campus, interviews and surveys conducted confirmed that some of the activities were now the beneficiaries' livelihood and uplifted their living conditions.

To further strengthen the community extension services BulSU - Hagonoy Campus, the researchers sought to analyze and examine the Strengths, Weaknesses, Opportunities, and Threats in implementing, monitoring, and evaluating its extension services as a basis for service enhancement.

\section{Theoretical framework}

Figure 1 shows the SWOT (Strengths, Weaknesses, Opportunities, and Threats) Analysis matrix, which will be utilized in analyzing the strengths, weaknesses, opportunities, and threats of the community extension services of BulSU-

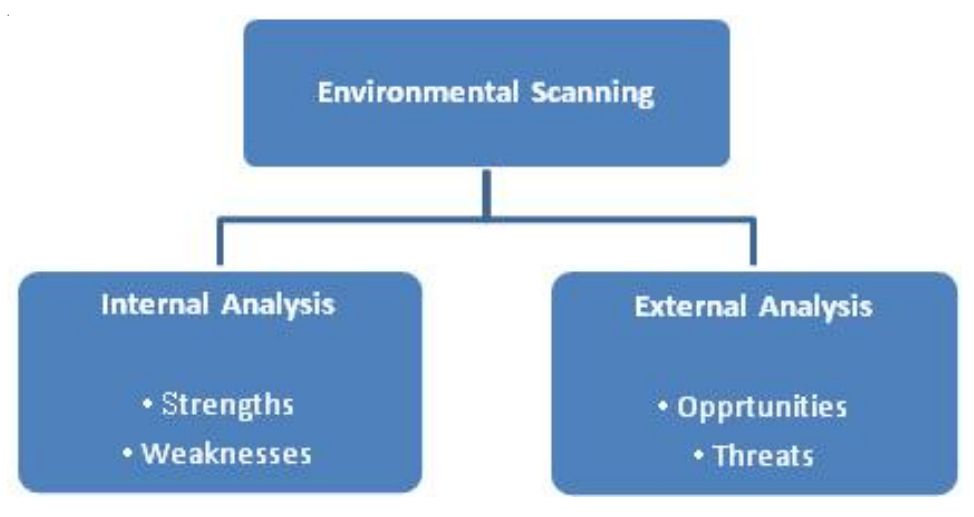

Figure 1: SWOT analysis

Source: https://www.managementstudyguide.com/swot-analysis.htm 
Hagonoy Campus to address what is insufficient, reduce risks and to gain the significant advantage of chances for success.

Applying this framework, the researchers came up with the research paradigm, as shown below:

\section{Research paradigm}

Figure 2 shows the paradigm of the study, which consists of three frames. The first frame consists of the input which is the community extension services of Hospitality and Tourism Management Program of BulSU Hagonoy Campus. The second frame includes the process on the conduct of SWOT Analysis in the implementation, monitoring, and evaluation in the community extension services of Hospitality and Tourism Management Program of BulSU-HC. The third frame is the expected output which is the enhanced community extension services of the Hospitality and Tourism Management Program BulSU-HC.

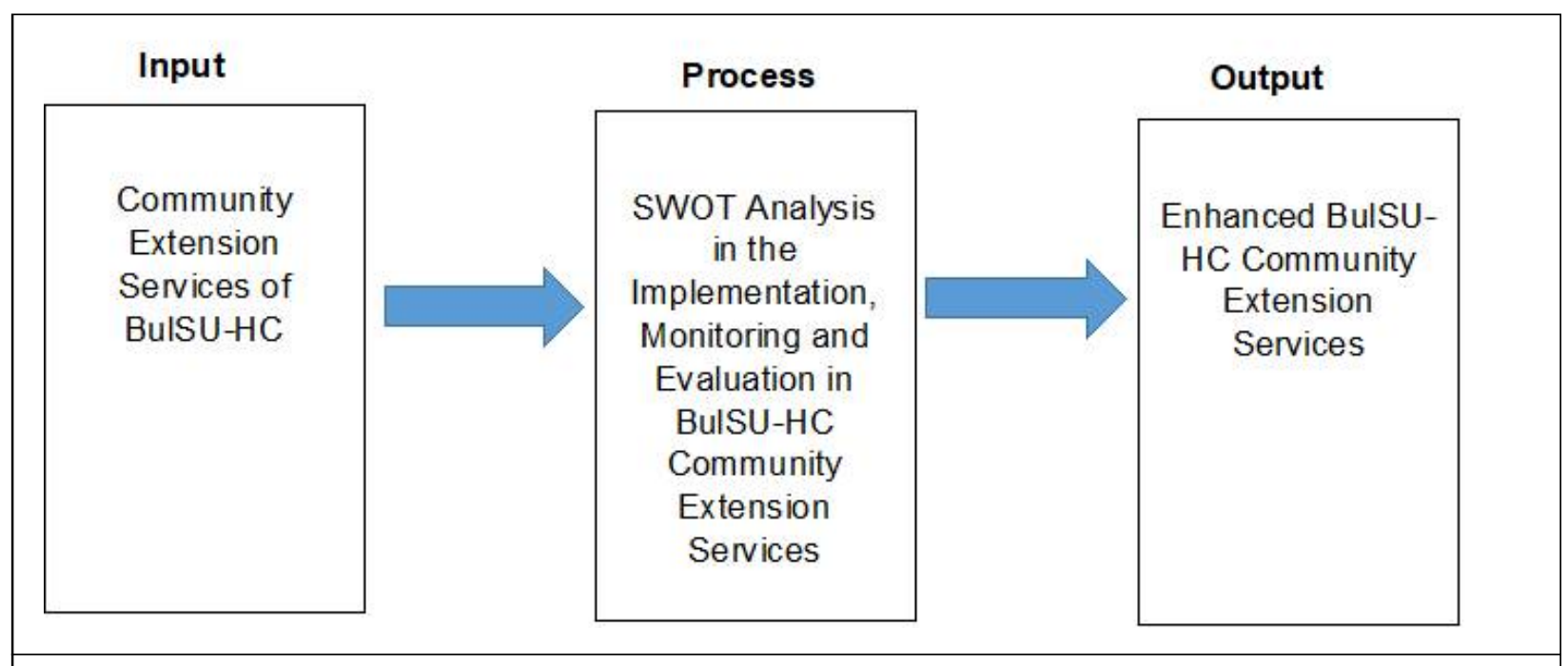

Figure 2: Research paradigm of the study

\section{Statement of the problem}

This study sought to examine and analyze the community extension services conducted by BulSU-Hagonoy Campus, particularly the Hospitality and Tourism Management Program, as the basis for service enhancement. Specifically, the study will seek answers to the following:

1. What is the demographic profile of respondents in terms of:

\section{1 age}

1.2 gender

\section{3 civil status}

1.4 educational qualification

2. What are the extension services provided by BulSU-Hagonoy Campus?

3. What is the extension approaches utilized by BulSU-Hagonoy Campus in terms of:

\section{1 monitoring}

\section{2 evaluation}

4. What are the strengths of community extension services does BulSU-Hagonoy Campus provide?

5. What are the weaknesses in the community extension services provided by BulSU-Hagonoy Campus?

6. What new opportunities exist for delivering better community extension services?

7. What are the emerging threats for community extension services? and;

8. What strategies can be proposed for the enhancement of BulSU-Hagonoy community extension services? 


\section{Scope and limitation of the study}

The study was conducted in the different Barangays in Hagonoy, Bulacan namely: Iba, Iba-Ibayo, Abulalas, Carillo, Sta.Elena, San Nicolas, Sagrada, Sta.Monica, Pugad and Tibgauin. The study will be focusing on the strengths, weaknesses, opportunities and threats in the implementation, monitoring and evaluation of the community extension services conducted by BulSU- Hagonoy Campus, which will serve as a basis for service enhancement. The study took place during S.Y. 2020-2021.

\section{Research methodology}

In gathering the data to answer and clarify the research problems, purposive selection was the sampling technique which will be employed in the investigation.

The respondents of this study will be 78 community extension participants from different barangays of Iba, IbaIbayo, Abulalas, Carillo, Sta.Elena, San Nicolas, Sagrada, Sta.Monica, Pugad and Tibgauin.

The survey questionnaires were distributed through the coordination of the Barangay Officials and some will be sent via emails.

A letter of request to conduct the study was prepared and was disseminated to the respondents. The questionnaires were administered and were retrieved personally and through email by the researchers.

\section{Results and discussion}

The majority of the respondents came from barangays Pugad, Sagrada Familia, Sta. Elena, Sta. Monica and Tibaguin with 12.8 percentage. $11.5 \%$ of the came from barangays Iba and San Nicolas, $7.7 \%$ from barangay Tampok, and 5.15 from Iba-Ibayo in Hagonoy, Bulacan. Greater percentage of the respondents are ages 41-50 with 23.1\%, 20.5\% are ages 25-30 and ages 31-35, 16.7\% for ages 36-40, 12.8\% for ages below 25 and 6.4\% for ages 51 and above.

For the extension services that have been provided by BulSU-Hagonoy, 50 out of the 78 respondents have participated in seminars for Climate Change Adaptation, 7 out of 78 respondents for trainings and seminars in Historical and Cultural Heritage Conservation, 53 out of 78 for Education which includes literacy trainings and seminars and values formation seminars, and 78 or all of the respondents have participated in the Innovation and Creativity which includes the livelihood and skills training \& seminars extension services. The data gathered revealed that out of the extension services conducted by the Hospitality and Tourism Program, the livelihood and skills training \& seminars are the most participated extension services.

In view of the approaches in monitoring and evaluating community extension services, the data gathered shown that monitoring and evaluation are often done through visit by the campus extension coordinator, using of monitoring and evaluation forms, and regular meetings with the community officials and evaluation through phone calls. Thus, use of social media and emails are seldom utilized as means of monitoring and evaluation. Data also revealed that monitoring of extension services are done monthly by the extension service coordinator.

\section{Analysis of the extension services strengths and weaknesses}

It has been found out that variety of extension services offered by the Hospitality and Tourism Program of BulSU Hagonoy Campus such as: seminars in climate change adaptation, trainings and seminars in historical and cultural heritage conservation, literacy trainings and seminars, values formation seminars, and livelihood and skills training and seminars, is the leading strength of the extension service program. Diversity in the selection of participant, sufficient funding from the University, Financial support from the partner non-government organization, and a regular monitoring and evaluation of the extension services are also among its many strengths.

Among the identified weaknesses, the disagreement of the respondents for lack of coordination from the community is $70.5 \%$, lack of participation from community is $69.2 \%$, unsustainability of the extension services provided is $69.2 \%$, and insufficient knowledge of speakers is $55.1 \%$. Based from the percentage of disagreement, the data shown indicates that the mentioned weaknesses could be regarded as strengths. However, a high percentage of agreement on the lack of preparation in extension activities conducted is one of the identified weakness of the extension service program. The researchers discovered that the strategy for the extension service program of the Hospitality and Tourism of BulSUHagonoy Campus is by assessing the need of the communities and deliver their needs through extension service activities. The extension program has a set schedule and deadlines in the accomplishment of extension services, but 
since their first step is to assess the needs of the communities, waiting for the respondents' reply in the needs analysis takes much time. Therefore, the preparation for the extension service activities usually has limited time.

\section{Analysis of the extension services threats and opportunities}

The favorable situation the extension service program has to offer its beneficiaries covers the additional income generating projects for the community, the chances given to participants on becoming entrepreneurs through the livelihood and skills training, the opportunity to gain new knowledge and skills in the field of hospitality and tourism and increase the level of employability. This is also a great deal of opportunity for the extension service program for the conduct of more sustainable extension service activities.

The threats which were realized during the conduct of the study consist of the pandemic, political instability, household problems/conflict by the participants, and difficulty in transportation since some of the barangay are located in islands.

Findings show that the training and visit system is one of the commonly employed of all extension techniques. However, with the current situation, extension activities should become accustomed to technological change. Considering the use of online platforms is one strategy suggested. Nevertheless, not all techniques are suitable for each barangay. Thus, the first step should be to determine the most applicable technique. Suppose technological change cannot be an option. In that case, the use of educational materials like bulletins, fact sheets, and pamphlets that can be distributed to participants, which can be used to strengthen information presented during orientation, can be designed.

To conclude, in response to the weakness of the extension program of the Hospitality and Tourism of BulSUHagonoy Campus with regards to the lack of preparation for the extension activities, it is highly recommended that the link between research and extension be strengthened. It would be easier to facilitate extension activities that are readily available and completed through series of studies. The classic picture of extension is when the researcher communicates his research information to the extensionist for transmittal to the beneficiaries.

\section{References}

Agholor, I. (2016). Accuracy, relevance and timeliness: Does extension practitioners satisfy clients? A case of farmers in Nkonkobe, South Africa. Journal of Social Science, 49(1-2), 53-57.

Ganpat, W., Webster, N. and Narine L.K. (2014). Farmers' Satisfcation with Extension Services in the Organization of Eastern Carribean States. Journal of International Agricultural and Extension Education, 21(13), 49.

Gurel, E. (2017). SWOT Analysis: A Theoretical Review. Journal of International Social Research, 10(51), 994-1006.

Kau, J., Mahlangu, S. and Maku, M. (2019). Strength, Weaknesses, Opportunities and Threats (SWOT) Analyses for mutliple extension services in high value crop programme: insight for pluralistic extension policy. Research Gate. DOI: 10.17159/2413-3221/2019/v47n3a513.

Kongnso, M.E., Ngala K.I. and Kongla, N.L. (2020).Agricultural Extension Approaches and Climate Change Communication within the Ndop Rice Sector, North West Region, Camerron. International Journal of Social Political and Economic Research, 7(2), 125-141.

Mueller, B., Gomez, M., and Ricketts, K. (2013). An Evaluation of Extension Services of the Colombian Coffee Grower Federation. https://agrilinks.org/sites/default/files/resource/files/EVAL\%20Colombia\%20-\%20FNC\%20\%20Final\%20Report\%202012_06_27.pdf

Odeleye, T. (2018). Extension's Role and stakeholder' intervention in climate change advocay. International Journal of Agriculture Environment and Food Sciences, 2(4), 174-176.

Panagiotou, G. (2003). Bringing SWOT into focus. Business Strategy Review, 14(2).

Ruedas-Declaro, M. (2019). Communication Modalities Used in the Delivery of Extension Programs to Small Scale Livestock Raiser: San Jose, Occidental Mindoro, Philippines. International Journal of Agricultural Extension, 7(1),39-44.

Cite this article as: Canet, Lena (2021). SWOT analysis of the community extension services conducted by hospitality and tourism management programs: Strategies for service enhancement. International Journal of Tourism and Hospitality. 1(3), 36-40. doi: 10.51483/IJTH.1.3.2021.36-40. 